\title{
Supravalvular aortic stenosis
}

\author{
Long-term results of surgical treatment
}

To determine long-term outcome after operation for supravalvular aortic stenosis, we reviewed the case histories of 80 patients who had repair of the localized form (group A) $(n=67)$ or diffuse form (group B) $(n=13)$ from 1956 to 1992, including 31 patients with the Williams-Beuren syndrome. Ages ranged from 7 months to 54 years (mean $=12.6$ years). Forty-six patients had one or more associated cardiovascular anomalies; the most common was aortic valve stenosis $(33.8 \%)$. Eighteen patients had 22 previous cardiovascular operations, and 28 patients had one or more additional anomalies repaired during their initial procedure at our institution. In group A, the aortic root was enlarged with a teardrop-shaped patch $(n=61)$ or a pantaloon-shaped patch $(n=6)$. In group B, patch enlargement of the aorta was confined to the root $(n=4)$ or extended into the ascending aorta or aortic arch $(n=7)$; one patient had a graft placed between the ascending and descending thoracic aorta and one patient had a left ventricular-aortic conduit. There were no deaths in group A; two patients in group B in whom patch enlargement was confined to the aortic root died during the operation $(2.5 \%)$. Follow-up extended to 33.4 years (mean $=14.2$ years); there were five late deaths in group $A$ and one in group $B$. Survival excluding operative mortality was $94 \%$ at 10 years and $91 \%$ at 20 years. All patients were in functional class I or II. There was no significant difference between patients with a teardrop-shaped or pantaloon-shaped patch in terms of late gradient, survival, or aortic insufficiency. By Cox multivariate model, the only independent predictor of late death for all patients was associated aortic valve disease $(p=0.02)$, which was also a risk factor for late reoperation $(p=0.02)$. In group $B$, overall survival was better in patients who received an extended patch versus aortic root patch only $(p=0.02)$. We reached the following conclusions: (1) Associated aortic valve disease was strongly correlated with late death and need for reoperation. (2) Both the teardrop-shaped and pantaloon-shaped patch techniques provide excellent long-term relief of localized supravalvular gradients and preservation of aortic valve competence. (3) In diffuse supravalvular aortic stenosis, aortic enlargement should be extended into the ascending aorta or beyond as required to relieve the gradient; some patients may require a graft or conduit. (4) Early surgical intervention before development of coronary artery disease or ventricular dysfunction may improve long-term survival. (J THORAC CardiovaSC SuRG 1994;107:10315)

Jacques A. M. van Son, MD, PhD (by invitation), Gordon K. Danielson, MD, Francisco J. Puga, MD, Hartzell V. Schaff, MD, Amita Rastogi, MD (by invitation), William D. Edwards, MD (by invitation), and Robert H. Feldt, MD (by invitation), Rochester, Minn.

From the Division of Thoracic and Cardiovascular Surgery, Division of Anatomic Pathology, and Section of Pediatric Cardiology, Mayo Clinic, Rochester, Minn.

Read at the Seventy-third Annual Meeting of The American Association for Thoracic Surgery, Chicago, Ill., April 25-28, 1993.

Address for reprints: Gordon K. Danielson, MD, Division of Thoracic and Cardiovascular Surgery, Mayo Clinic, 200 First Street, SW, Rochester, MN 55905.

Copyright ${ }^{\circledR} 1994$ by Mosby-Year Book, Inc.

$0022-5223 / 94 \$ 1.00+.10 \quad \mathbf{1 2} / 6 / 50457$
Ourgical reconstruction of the aortic root for congenital discrete supravalvular aortic stenosis (SAS) was first performed in 1956 by Kirklin ${ }^{1}$ at the Mayo Clinic, using a teardrop-shaped patch, and later reported by several other groups. ${ }^{2-4}$ In 1964 Shumacker and Mandelbaum ${ }^{5}$ and McGoon at the Mayo Clinic independently treated patients with the diffuse form of SAS with an extended patch into the entire ascending aorta. Doty, Polansky, and Jenson, ${ }^{6}$ in 1977 , reported use of a pantaloon-shaped patch for relief of discrete SAS. Although the early and 

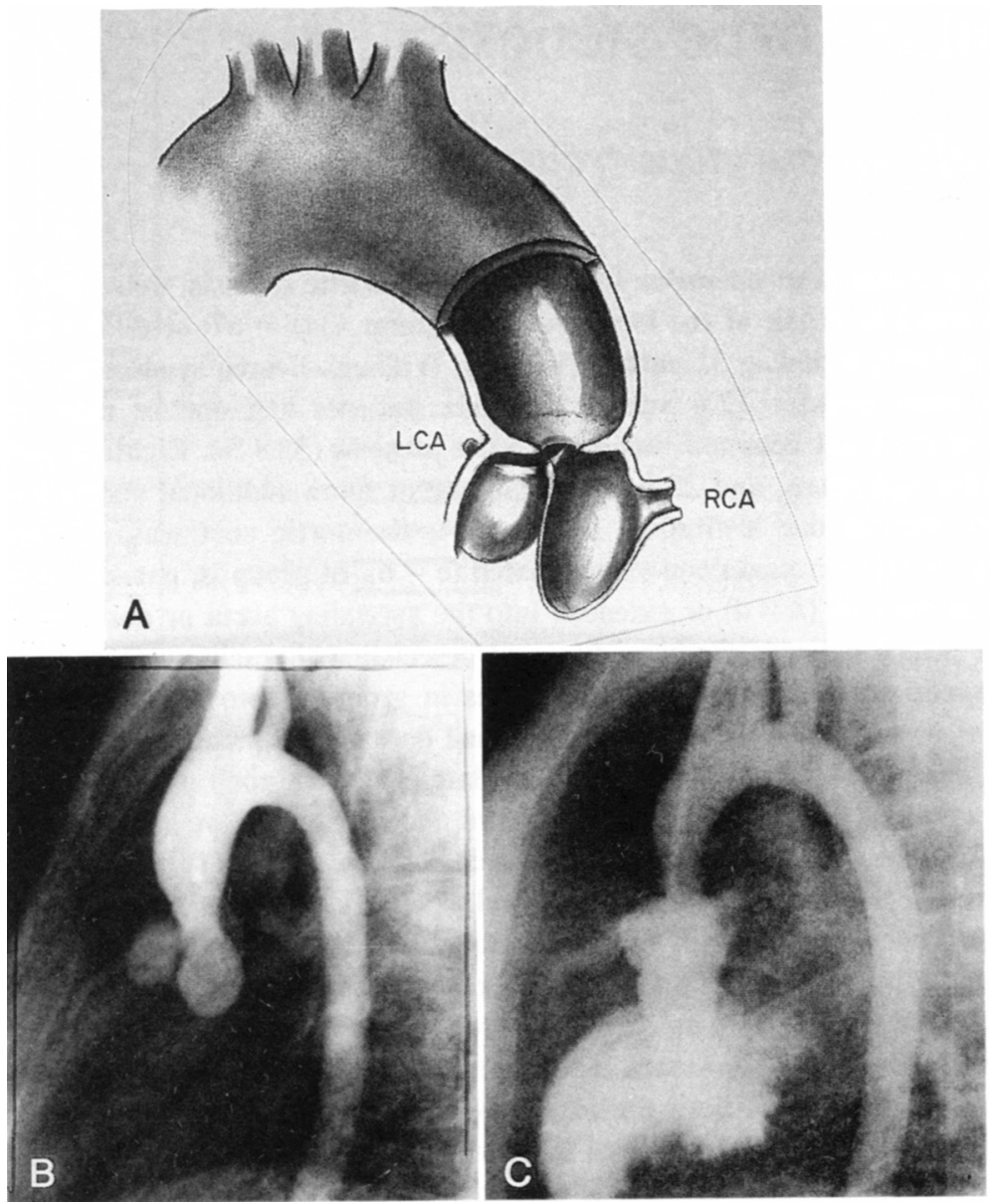

Fig. 1. Discrete SAS. A, Diagram. B, Lateral view of aortogram. Note the dilated right coronary artery and the faintly visualized left coronary artery, whose ostium was partially obstructed by the supravalvular membrane. C, Lateral view of aortogram of another patient with unobstructed coronary ostia showing dilatation of both coronary arteries. $R C A$, right coronary artery; $L C A$, left coronary artery.

intermediate results of the teardrop-shaped and pantaloon-shaped patch techniques for relief of discrete SAS have been reported to be excellent, ${ }^{1-10}$ little long-term follow-up information is available..$^{1-13}$ In addition, the rarity of diffuse SAS has made it difficult to obtain satisfactory data on the results of surgical treatment of this lesion. Controversy exists regarding the best operative technique for both lesions. To determine the long-term effects of surgical treatment of discrete and diffuse SAS on left ventricular-aortic systolic gradients, need for reoperation, and survival, we analyzed the data of all patients who have had surgical treatment of SAS at the Mayo Clinic.

\section{Patients and methods}

Between 1956 and 1992, 80 patients underwent operative treatment for congenital SAS at the Mayo Clinic. Case histories of 16 of these patients have been reported previously. ${ }^{9}$ The lesions were classified according to the system devised by Lev, ${ }^{14}$ who first reported that SAS may occur as a localized lesion (Fig. 1) and as part of generalized hypoplasia of the entire ascending aorta and beyond (Fig. 2). The latter lesion was designated diffuse in this report. Sixty-seven patients (83.8\%) had localized SAS and $13(16.2 \%)$ had diffuse SAS. Seven patients with the diffuse form had a previously described anatomic variant in which narrowing of the aorta extended into the aortic arch and additional stenoses were present in the proximal arch vessels (Fig. 3). ${ }^{15}$

Fifty-two patients $(65 \%)$ were male and $28(35 \%)$ were female. The ages of the patients ranged from 7 months to 54 years (mean $=12.6 \pm 10.6$ years). Forty-six of the 80 patients $(57.5 \%)$ had one or more associated congenital cardiovascular anomalies (Table I). The most common associated anomaly was valvular aortic stenosis, which was present in $27(33.8 \%)$ patients; 22 of the 27 patients had a bicuspid aortic valve and one had a unicuspid valve (Table II). In addition, dilatation of the sinuses of Valsalva and multiple abnormalities of one or both coronary arteries were common (Table II).

Thirty-one patients had the Williams-Beuren syndrome, in which SAS is associated with a typical facial appearance and mental retardation. ${ }^{4,16,17}$ In this syndrome, associated cardio- 


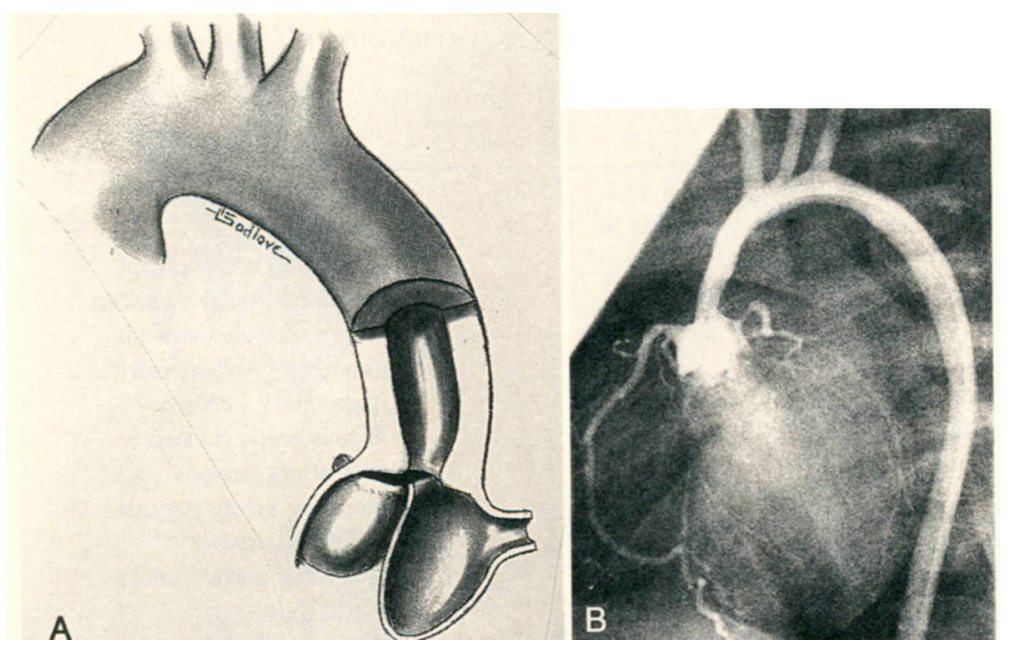

Fig. 2. Diffuse SAS. A, Diagram. B, Lateral view of aortogram showing dilated right coronary artery and faintly visualized left coronary artery.
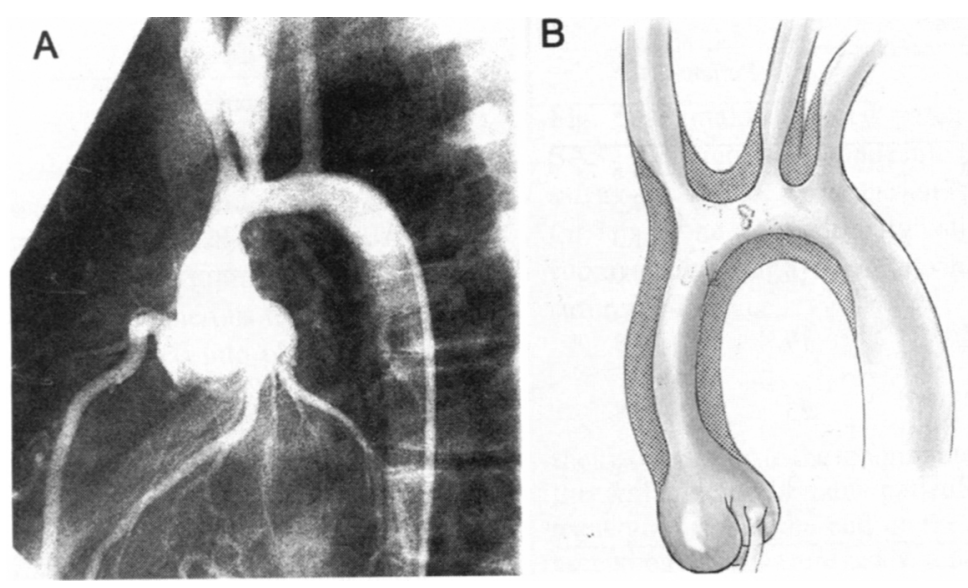

Fig. 3. Diffuse SAS with arch vessel involvement. A, Lateral view of aortogram showing proximal stenoses of the innominate artery and the left common carotid artery. B, Diagram.

vascular or other anomalies were found in all patients (Table III). A familial occurrence of the syndrome was observed in three patients. One of the latter was mentally retarded, compared with 26 of the 28 patients with nonfamilial WilliamsBeuren syndrome. Twenty-four patients with the syndrome were examined by a medical geneticist for confirmation of the diagnosis and genetic counseling.

Seventy-seven patients underwent their first operation for SAS at our institution. Three patients (two with discrete and one with diffuse SAS) had previously been operated on for attempted repair at other institutions and had a persistent severe left ventricular-ascending aortic gradient. Including these three patients, 18 patients had 22 previous cardiovascular operations (Table IV).

Twenty-three patients $(28.8 \%)$ were free of symptoms; 40 (50\%) were in New York Heart Association (NYHA) functional class II, $16(20 \%)$ were in class III, and $1(1.2 \%)$ was in class IV. Systolic left ventricular-aortic gradients ranged from
45 to $140 \mathrm{~mm} \mathrm{Hg}$ (mean $=94$ ). Symptoms are compared to systolic gradients in Table V; there was no correlation between symptoms and gradients. Three patients $(3.8 \%)$ had a history of bacterial endocarditis. Normal sinus rhythm was present in 79 patients $(98.8 \%)$ and one patient $(1.2 \%)$ had received a pacemaker for sick sinus syndrome.

All patients underwent preoperative cardiac catheterization and, more recently, two-dimensional echocardiography with Doppler and color flow imaging. The thoracoabdominal aorta as well as the right ventricular outflow tract and pulmonary arteries were evaluated angiographically in all 31 patients with the Williams-Beuren syndrome.

In the majority of patients, intraoperative pressures were measured in the cardiac chambers before $(n=66 ; 82.5 \%)$ and after $(n=78 ; 97.5 \%)$ repair. Information concerning coronary arterial anatomy was obtained from preoperative angiography and from intraoperative inspection of the coronary arteries and their ostia. Early echocardiography (within 2 weeks of opera- 
Table I. Associated congenital cardiovascular anomalies (46 patients)

\begin{tabular}{lcc}
\hline & \multicolumn{2}{c}{ Patients } \\
\cline { 2 - 3 } Anomaly & No. & $\%$ \\
\hline Valvular aortic stenosis & 27 & 33.8 \\
Branch and/or peripheral & 15 & 18.8 \\
$\quad$ pulmonary artery stenosis* & & \\
Subvalvular aortic stenosis & 10 & 12.5 \\
Coarctation of aorta & 7 & 8.8 \\
Mitral valve stenosis & 7 & 8.8 \\
Aortic arch vessel stenosis* & 7 & 8.8 \\
Infundibular and/or valvular & 6 & 7.5 \\
$\quad$ pulmonary stenosis* & & \\
Patent ductus arteriosus & 2 & 2.5 \\
Ventricular septal defect & 1 & 1.3 \\
Partial atrioventricular canal & 1 & 1.3 \\
Aberrant right subclavian & 1 & 1.3 \\
$\quad$ artery & & \\
\hline
\end{tabular}

${ }^{*}$ Found only in Williams-Beuren syndrome.

Table II. Sinus of Valsalva, aortic valve, and coronary artery anomalies

\begin{tabular}{lrr}
\hline \multicolumn{1}{c}{ Anomaly } & \multicolumn{2}{c}{ Patients } \\
\cline { 2 - 3 } & \multicolumn{1}{c}{ No. } & $\%$ \\
\hline Sinus of Valsalva dilatation & 67 & 83.8 \\
Bicuspid aortic valve & 22 & 27.5 \\
$\quad$ Unicuspid aortic valve & 1 & 1.3 \\
$\quad$ Left coronary artery & 16 & 20.0 \\
$\quad$ dilatation & 19 & 23.8 \\
$\quad$ Left coronary artery ostial & & \\
$\quad$ stenosis & 23 & 28.8 \\
$\quad \begin{array}{l}\text { Right coronary artery } \\
\quad \text { dilatation }\end{array}$ & 5 & 6.3 \\
$\quad \begin{array}{l}\text { Right coronary artery ostial } \\
\quad \text { stenosis }\end{array}$ & & \\
\hline
\end{tabular}

tion) was performed in 17 patients $(21.3 \%)$. Late echocardiography or late cardiac catheterization (or both) was performed in 50 patients $(62.5 \%)$ and 14 patients (17.5\%), respectively. Follow-up data were collected by examination and questionnaires completed by patients/parents and referring physicians. Telephone calls were made to complete data acquisition when necessary.

Means and standard deviations were calculated. Variables that were analyzed with the $\chi^{2}$ or Student's $t$ test were as follows: age; sex; presence of associated cardiovascular anomalies; presence of associated aortic valve disease; form of SAS (localized or diffuse); preoperative NYHA functional class; previous cardiovascular operations; preoperative, intraoperative prerepair, intraoperative postrepair, and late postoperative left ventricular-aortic gradients; presence of Williams-Beuren syndrome; teardrop- versus pantaloon-shaped patch; aortic root patch only versus extended patch repair; year of operation; need for previous or concomitant aortic valvotomy; and need for previous or concomitant aortic valve replacement. A $p$ value equal to or less than 0.05 was considered significant. Variables with a
Table III. Associated anomalies in Williams-Beuren syndrome (31 patients)

\begin{tabular}{lcc}
\hline & \multicolumn{2}{c}{ Patients } \\
\cline { 2 - 3 } Anomaly & No. & $\%$ \\
\hline Dental abnormalities & 28 & 90.3 \\
Mental retardation & 27 & 87.1 \\
Branch and/or peripheral & 15 & 48.4 \\
$\quad$ pulmonary artery stenosis & & \\
Aortic arch vessel stenosis & 7 & 22.6 \\
Infundibular and/or valvular & 6 & 19.4 \\
$\quad$ pulmonary stenosis & & \\
Valvular aortic stenosis & 4 & 12.9 \\
Renal artery stenosis & 3 & 9.7 \\
Mesenteric artery stenosis & 3 & 9.7 \\
Familial occurrence & 3 & 9.7 \\
Subvalvular aortic stenosis & 1 & 3.2 \\
Coarctation of aorta & 1 & 3.2 \\
Patent ductus arteriosus & 1 & 3.2 \\
\hline
\end{tabular}

Table IV. Previous cardiovascular operations

\begin{tabular}{lc}
\hline \multicolumn{1}{c}{ Operation } & $\begin{array}{c}\text { No. of } \\
\text { patients }\end{array}$ \\
\hline Aortic valvotomy & 10 \\
Coarctation repair & 6 \\
Attempted repair of SAS & 3 \\
Repair of subvalvular aortic stenosis & 2 \\
Aortic valve replacement & 1 \\
\hline
\end{tabular}

Table V. Comparison of symptoms and systolic left ventricular-aortic gradients

\begin{tabular}{cccc}
\hline & \multicolumn{2}{c}{ Patients } & Mean gradient \\
\cline { 2 - 3 } Symptoms & No. & $\%$ & $(m m \mathrm{Hg} \pm$ SD $)$ \\
\hline Asymptomatic & 23 & 28.8 & $91 \pm 30$ \\
Symptomatic & 57 & 71.2 & $95 \pm 37$ \\
Dyspnea & 54 & 67.5 & $95 \pm 32$ \\
Angina & 14 & 17.5 & $99 \pm 31$ \\
(Pre)syncope & 12 & 15.0 & $95 \pm 36$ \\
\hline
\end{tabular}

$p$ value less than 0.1 were reanalyzed by multivariate stepwise regression analysis. Survival estimates were made with the Kaplan-Meier method and comparisons between survival distributions were made with the log-rank and Gehan Wilcoxon tests.

Operative techniques. Standard techniques for cardiopulmonary bypass were used. Profound hypothermia and circulatory arrest were added for some patients who underwent placement of ascending-descending aorta grafts or aortic arch reconstructions. Cold potassium crystalloid or blood cardioplegia has been used for myocardial protection since 1977. In patients with the discrete form of SAS, an oblique incision was made in the ascending aorta and extended well down into the noncoronary sinus of Valsalva (Fig. 4). This incision divided the 


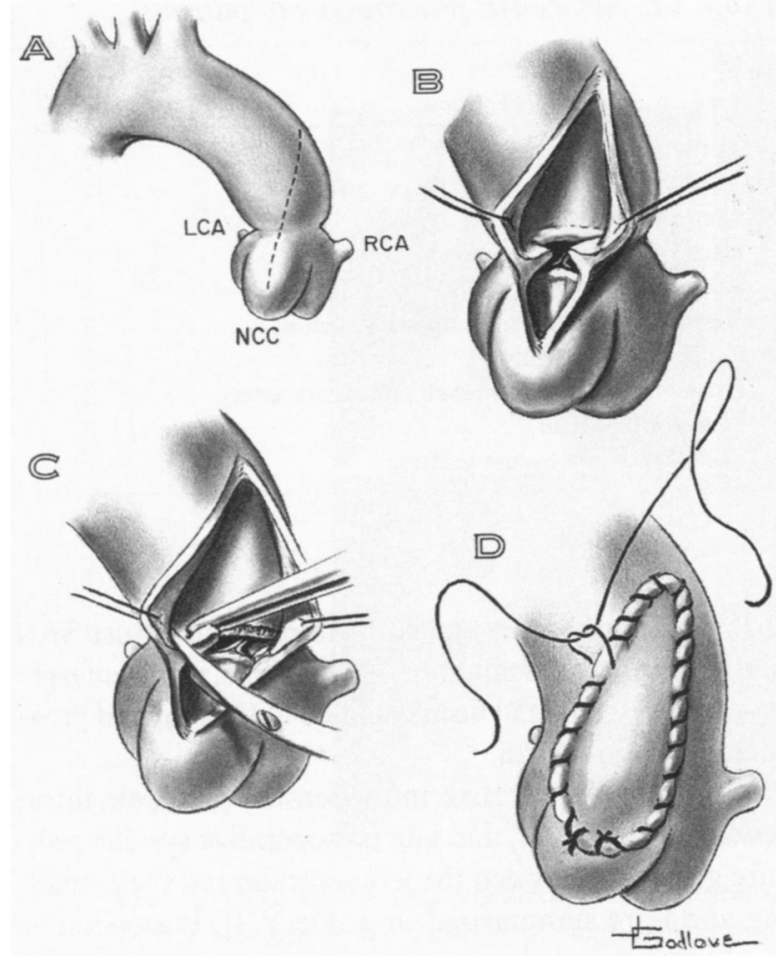

Fig. 4. Teardrop-shaped patch repair of discrete form of SAS. A, An incision is made in the proximal ascending aorta and carried down into the noncoronary sinus of Valsalva. $\mathbf{B}$, The edges of the incision are retracted showing the supravalvular ridge. $C$, The stenotic ridge is excised. D, A generous teardrop-shaped autologous pericardial patch is sutured into place. $L C A$, left coronary artery; $R C A$, right coronary artery; $N C C$, noncoronary cusp.

stenotic ridge, which was then excised as much as possible, especially any portions blocking access to the left or, less frequently, right sinus, to release and lengthen the coronary cusp(s) and to relieve coronary ostial obstruction. Care was taken to avoid damage to the aortic valve apparatus and the coronary ostia. Subsequently, a generous teardrop-shaped patch was sutured into the incision to increase the circumference of the aorta. Although Ivalon, Teflon, and Dacron fabric were used as patch material in the past, untreated autologous pericardium, which has given excellent early and late results, has been our prosthetic material of choice for many years. ${ }^{18}$

A technique originally described by Doty, Polansky, and Jenson ${ }^{6}$ has been used in seven cases. The supravalvular stenotic ridge was divided twice, at the noncoronary sinus of Valsalva and at the right sinus of Valsalva just anterior to the commissure between the right and left coronary cusps (Fig. 5). A pantaloon-shaped patch was sutured into both the noncoronary and right sinuses to increase the circumference of the aorta.

Treatment of the diffuse form of SAS has evolved with increasing experience in its management. Some of the early cases had only enlargement of the aortic root, resulting in significant gradients at the distal end of the patch. Patches were

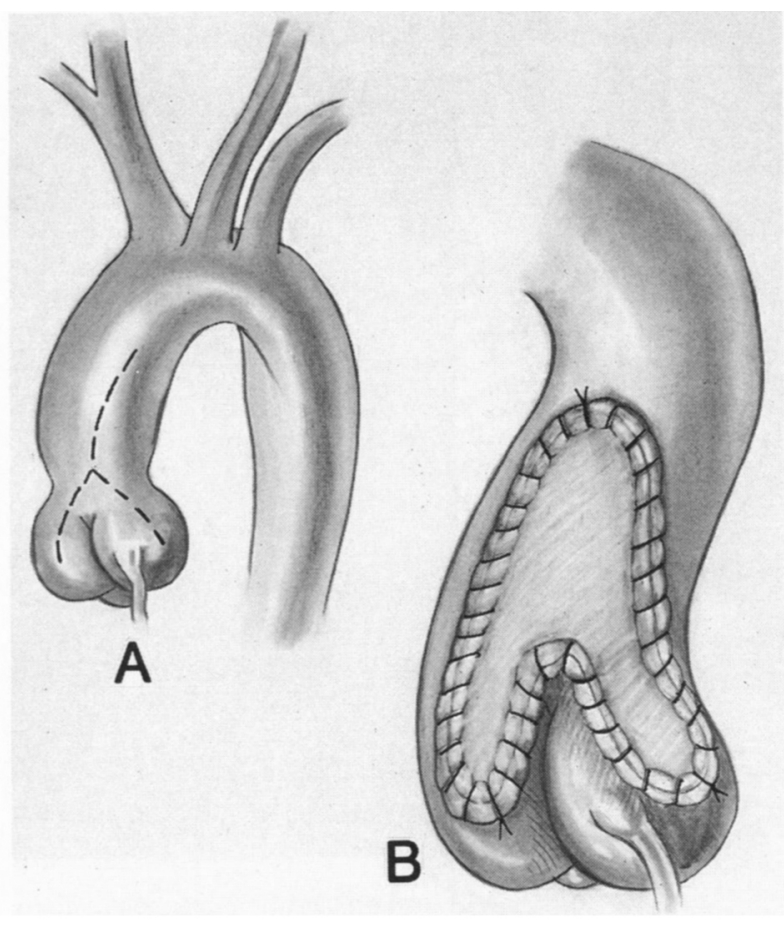

Fig. 5. Pantaloon-shaped patch repair of discrete form of SAS. A, An incision is made into the noncoronary sinus of Valsalva as in Fig. 4. An extension is made into the right sinus to the left of the right coronary ostium. B, After excision of the supravalvular ridge, a pantaloon-shaped pericardial patch is sutured into place.

then extended up to the innominate artery or into the aortic arch; this was effective in many patients, but a few still had a significant gradient at the end of the patch. Currently, the entire ascending aorta is enlarged by a patch, usually of vascular graft material. If necessary, the entire aortic arch, the proximal innominate artery, and the proximal left common carotid artery are also enlarged (Fig. 6). If the diffuse form extends beyond the aortic arch, a graft is placed between the ascending and descending aorta, with side branches to the arch vessels as necessary (Fig. 7). For some patients with diffuse SAS and valvular or subvalvular aortic stenosis operated on early in the series, a Hancock conduit (Johnson \& Johnson Cardiovascular, King of Prussia, $\mathrm{Pa}$.) was inserted between the left ventricular apex and the supraceliac abdominal aorta.

Operative findings and procedures. Of the prior 22 cardiovascular operations, one or more had been performed through a median sternotomy in 13 patients. Twenty-eight patients had one or more additional anomalies repaired during their initial procedure at our institution (Table VI). In all patients with SAS there was a supravalvular ridge that drew the commissures of the aortic valve together at their superior ends. In the majority of patients, this ridge was more prominent above the left coronary cusp. Sinus of Valsalva, aortic valve, and coronary artery anomalies were commonly associated (Table II). Sixty-one of the 67 patients with discrete SAS underwent enlargement of the 


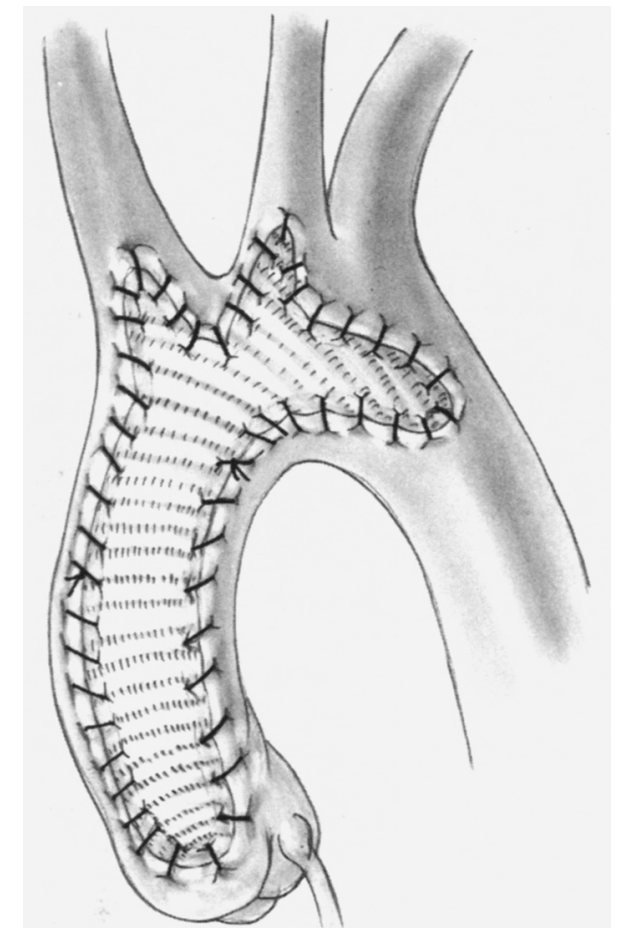

Fig. 6. Repair of diffuse SAS with involvement of the proximal arch vessels by means of a Dacron patch carried into the aortic arch and proximal innominate and left common carotid arteries.

aortic root with a teardrop-shaped patch and the other six received a pantaloon-shaped patch.

Among the 13 patients with diffuse SAS, the aortic root and proximal ascending aorta were enlarged in four with a teardropshaped $(n=3)$ or a pantaloon-shaped $(n=1)$ patch. In five other patients, the ascending aorta and proximal aortic arch were enlarged with a patch; in two of these, the innominate artery was enlarged with a separate patch. In two additional patients, the patch enlargement incorporated the ascending aorta, aortic arch, innominate artery, and proximal left common carotid artery. One patient, after an attempted repair of SAS elsewhere, received a graft between the ascending and descending thoracic aorta with side branches into the innominate artery and the left common carotid artery. The remaining patient, after valvotomy for aortic stenosis and an attempted repair of SAS elsewhere, received a left ventricular-supraceliac aortic valved conduit.

The types of material used in the 78 patients who underwent patch enlargement of the aorta are listed in Table VII. Two patients with the Williams-Beuren syndrome had patch enlargement of the main pulmonary artery and bifurcation and the main pulmonary artery and left pulmonary artery, respectively (Table VI, patch enlargement of branch pulmonary artery).

\section{Results}

Early results. There were two hospital deaths (2.5\%). Both resulted from intraoperative cardiac failure in the
Table VI. Associated procedures (28 patients)

\begin{tabular}{lc}
\hline \multicolumn{1}{c}{ Procedure } & $\begin{array}{c}\text { No. of } \\
\text { patients }\end{array}$ \\
\hline Aortic valve replacement & 14 \\
Aortic valvotomy & 12 \\
Aortic valve repair & 1 \\
Aortic valve decalcification & 1 \\
Konno-Rastan operation & 1 \\
Resection infundibular pulmonary stenosis & 3 \\
Pulmonary valvotomy & 2 \\
Patch enlargement of branch pulmonary artery & 2 \\
Mitral valve repair & 2 \\
Coronary artery bypass grafting & 1 \\
\hline
\end{tabular}

early part of the series and both patients had diffuse SAS and associated anomalies. In both patients, patch enlargement of the aorta had been confined to the root and proximal ascending aorta.

The mean preoperative, intraoperative prerepair, intraoperative postrepair, and late postoperative systolic pressure gradients between the left ventricle and the ascending aorta are summarized in Table VIII. Postoperative morbidity included reoperation for persistent bleeding $(n=2)$ and hemodynamic instability necessitating delayed sternal closure $(n=1)$.

Late results. Follow-up ranged from 8 months to 33.4 years (mean $=14.2$ years). Six patients $(7.5 \%$ ) (five with discrete SAS and one with diffuse SAS) died late: after aortic valve replacement $(n=2)$, from left coronary artery disease and myocardial infarction $(n=1$, age 39 years), from embolism with stroke from a prosthetic aortic valve $(n=1)$, from congestive heart failure caused by a stenotic bicuspid aortic valve and hypoplastic anulus $(n=1)$, and from endocarditis of an aortic valve prosthesis $(n=1,17$ years after the operation). Autopsies were obtained in six of the eight patients who died (one early and five late deaths). In all six, there was evidence of coronary artery disease: mild ( $n=1$, aged 3 years) and severe ( $n=5$, aged 20 to 52 years). In one patient, coronary artery disease was the direct cause of death; in the other five it was associated with myocardial fibrosis and localized healed infarctions. Overall survival, including early mortality, was $92 \%$ at 10 years and $88 \%$ at 20 years. Survival excluding early mortality was $94 \%$ at 10 years and $91 \%$ at 20 years (Fig. 8). There was a significant difference in survival between patients who had associated aortic valve disease (stenosis with or without insufficiency) and those who did not ( $p=0.01)$ (Fig. 9). There was no difference in late survival between patients with localized and diffuse SAS $(p=0.6)$ (Fig. 10). The only predictor of late death by both univariate and multivariate 


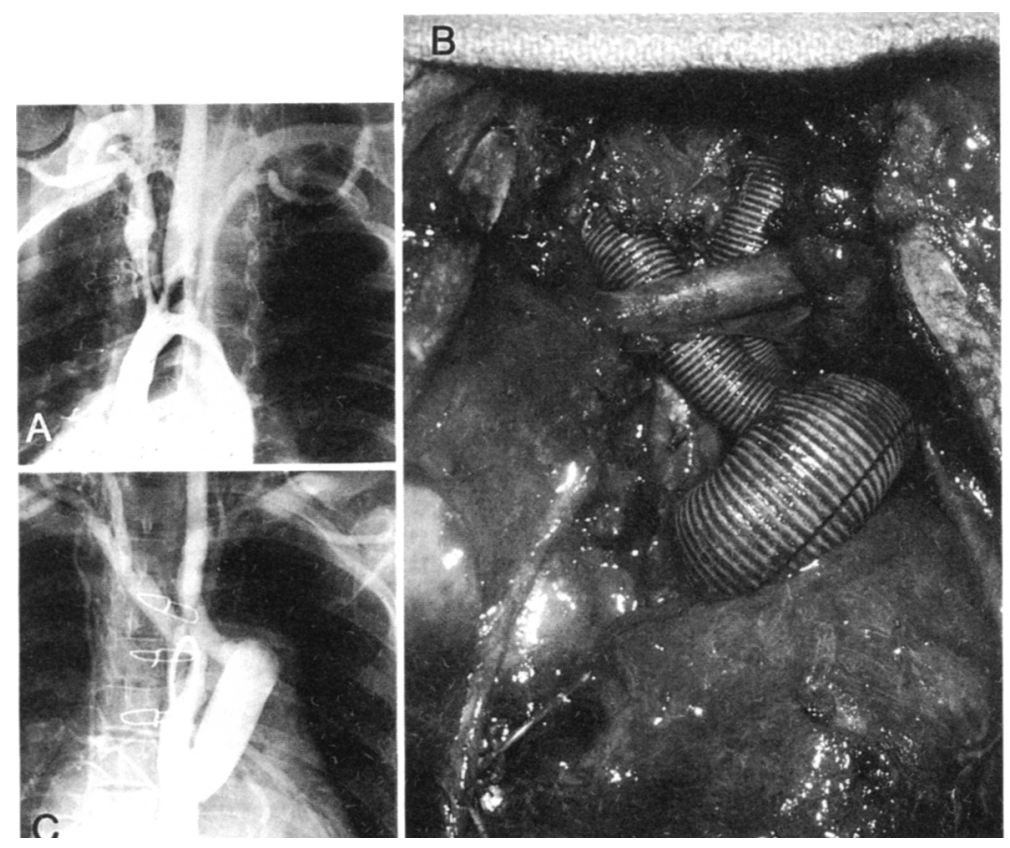

Fig. 7. Diffuse SAS involving all three arch vessels and the proximal descending thoracic aorta. A, Anteroposterior view of aortogram. B, Operative photograph showing Dacron graft between ascending aorta and descending aorta with side branches to innominate and common carotid arteries. C, Postoperative anteroposterior view of aortogram showing unobstructed blood flow to arch vessels and descending thoracic aorta.

analysis was aortic valve disease $(p=0.05$ and 0.02 , respectively).

The late mean left ventricular-aortic gradient was lower in the patients with localized SAS $(15 \pm 12 \mathrm{~mm}$ $\mathrm{Hg})$ than in those with diffuse SAS $(30 \pm 28 \mathrm{~mm} \mathrm{Hg})$ $(p=0.01)$. There was no significant difference in late mean left ventricular-aortic gradients between patients who had a teardrop-shaped patch $(n=62)$ versus a pantaloon-shaped patch $(n=7)$ (mean $18 \pm 16 \mathrm{~mm} \mathrm{Hg}$ versus $9 \pm 10 \mathrm{~mm} \mathrm{Hg}$, respectively) $(p=0.2) ; 20$ of these patients had associated aortic valve disease. Late aortic insufficiency, present in 22 patients, was mild in 18 , moderate in 1 , and severe in 3 . All patients with aortic insufficiency had associated aortic stenosis; no patient with a normal aortic valve had late aortic insufficiency. There was no significant difference in late development or progression of aortic insufficiency between patients who had a teardrop-shaped patch versus a pantaloon-shaped patch $(p=0.9)$.

The two operative survivors with diffuse SAS in whom patch enlargement of the aorta had been confined to the aortic root and proximal ascending aorta underwent reoperation for persistent left ventricular-aortic gradients of 115 and $75 \mathrm{~mm} \mathrm{Hg}$. In the first patient, the ascending aorta, aortic arch, and innominate artery were enlarged
Table VII. Patch material

\begin{tabular}{lc} 
Material & $\begin{array}{c}\text { No. of } \\
\text { patients }\end{array}$ \\
\hline Autologous pericardium & 42 \\
Teflon patch & 17 \\
Dacron patch & 11 \\
Ivalon patch & 3 \\
Albumin-coated Dacron patch & 2 \\
Bovine pericardium & 2 \\
Dura mater & $\frac{1}{78^{*}}$ \\
Total & \\
\hline
\end{tabular}

*The remaining two patients had a left ventricular-aortic conduit and an ascending-descending thoracic aortic graft.

with a long Dacron patch, reducing the postoperative left ventricular-descending aortic gradient to $25 \mathrm{~mm} \mathrm{Hg}$. In the second patient, a Dacron graft was placed between the ascending and descending thoracic aorta with a side branch to a proximally stenotic innominate artery, completely eliminating the gradient.

Fourteen patients, including the two mentioned earlier, underwent one to four reoperations, the majority for aortic valvular disease (Table IX). Reasons for mechanical valve rereplacement included outgrowth of the prosthesis, stenosis from pannus formation, and endocarditis. 


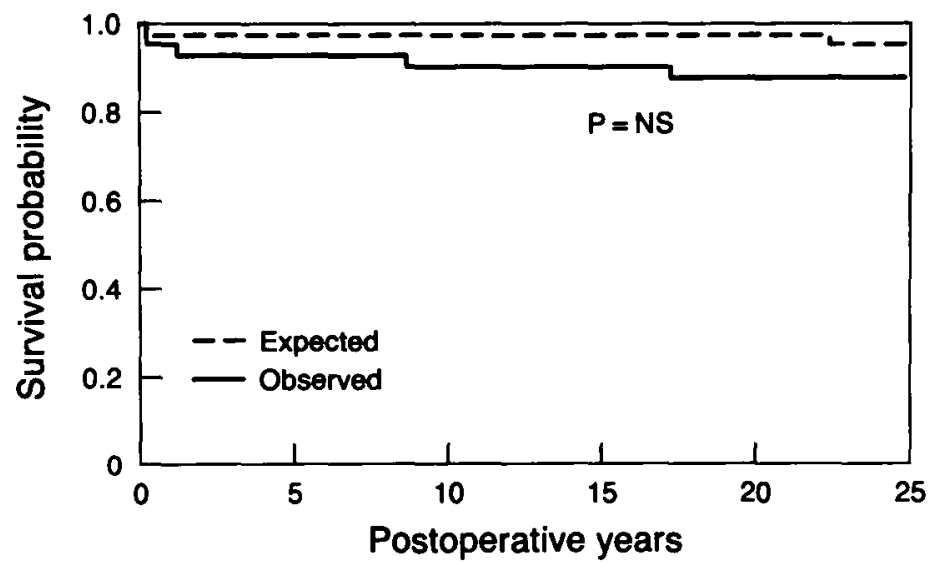

Fig. 8. Survival probability for patients excluding operative mortality. Expected survival in an age-and sex-matched control population is also shown.

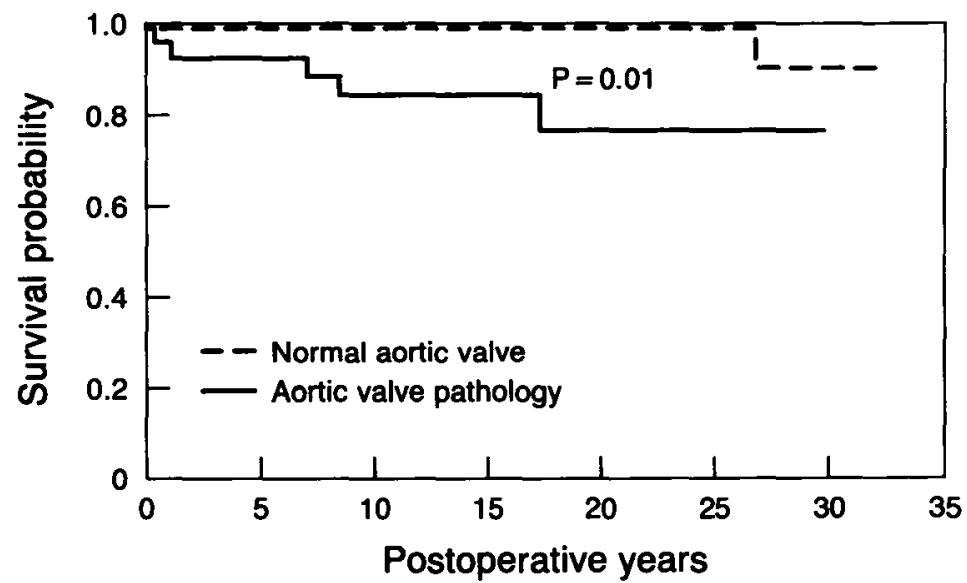

Fig. 9. Survival probability excluding operative mortality in patients with and without aortic valve disease.

Table VIII. Mean left ventricular-aortic gradients

\begin{tabular}{|c|c|c|c|c|}
\hline \multicolumn{2}{|c|}{ Measurements } & \multirow{2}{*}{$\begin{array}{l}\text { Localized } S A S \\
(\mathrm{~mm} \mathrm{Hg} \pm S D)\end{array}$} & \multirow{2}{*}{$\begin{array}{c}\text { Diffuse SAS } \\
(m m H g \pm S D)\end{array}$} & \multirow[b]{2}{*}{ p Valuet } \\
\hline Time & No. of patients & & & \\
\hline Preoperative* & 80 & $95 \pm 36$ & $93 \pm 38$ & NS \\
\hline Intraoperative prerepair & 66 & $70 \pm 30$ & $69 \pm 28$ & NS \\
\hline Intraoperative postrepair & 78 & $23 \pm 20$ & $29 \pm 25$ & NS \\
\hline Late postoperative $\dagger$ & 58 & $15 \pm 12$ & $30 \pm 28$ & 0.01 \\
\hline
\end{tabular}

$S D$, Standard deviation; $N S$, not significant.

*Catheterization $(n=80)$ and echocardiography $(n=21)$.

†Catheterization $(n=14)$ and echocardiography $(n=50)$.

$\ddagger$ Localized or diffuse SAS.

A left ventricular-supraceliac aortic conduit was implanted at reoperation in two patients, one with discrete SAS and additional subaortic and valvular aortic obstructions and one with discrete SAS and valvular aortic obstruction. Risk factors for reoperation by univariate analysis were associated aortic valve disease $(p=0.05)$, presence of late left ventricular-aortic gradient greater than $34 \mathrm{~mm} \mathrm{Hg}(p=0.05)$, absence of Williams-Beuren syndrome $(p=0.007)$, and need for previous or concomitant aortic valvotomy or aortic valve replacement 


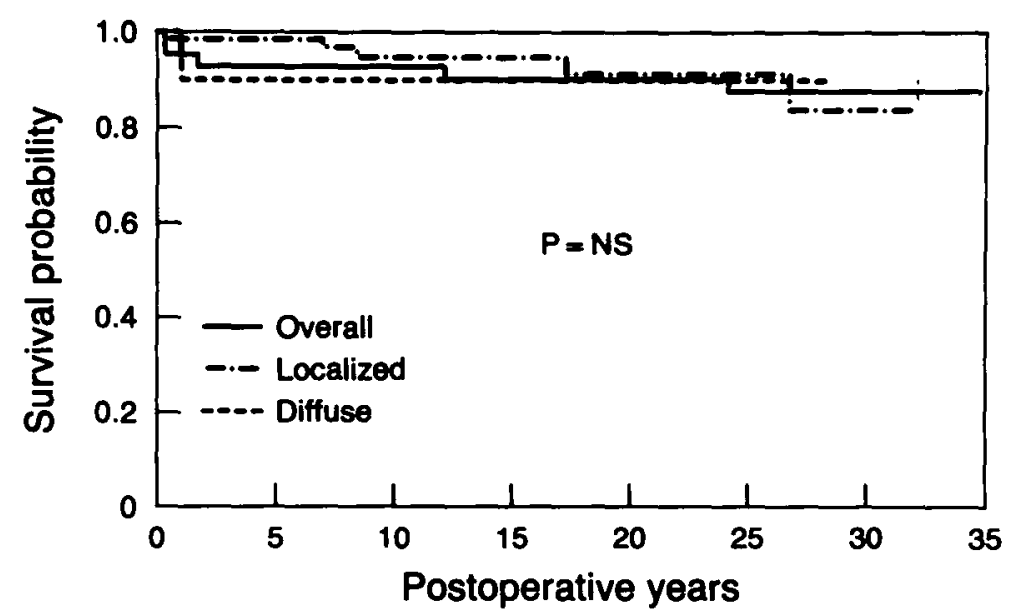

Fig. 10. Survival probability excluding operative mortality for the overall series and for patients with the localized and diffuse forms of SAS. There was no statistically significant difference $(P=N S)$ between these groups.

Table IX. Reoperations (14 patients)

\begin{tabular}{|c|c|c|c|c|}
\hline $\begin{array}{l}\text { No. of } \\
\text { patients }\end{array}$ & Reoperation I & Reoperation 2 & Reoperation 3 & Reoperation 4 \\
\hline 2 & $\operatorname{AVR}(\mathrm{M}, \mathrm{H})$ & & & \\
\hline 1 & $\operatorname{AVR}(M)+M V P$ & & & \\
\hline 1 & AVR (M) + LV myectomy & & & \\
\hline 1 & $\begin{array}{l}\text { Conduit valve replacement } \\
\text { (M) }\end{array}$ & & . & \\
\hline 1 & CABG & & & \\
\hline 1 & Patch into $\mathrm{AA}$ and InnA & & & \\
\hline 1 & AVR (M) & AICD & & \\
\hline 1 & $\operatorname{AVR}(\mathrm{M})$ & Secondary AVR (M) & & \\
\hline 1 & LV-aortic conduit (P) & Conduit valve replacement (M) & & \\
\hline 1 & AA-DA graft & $\begin{array}{l}\text { Removal graft and patch into AA } \\
\text { and InnA }\end{array}$ & & \\
\hline 1 & Secondary AVR (M) & Tertiary AVR (M) & Quaternary AVR (H) & \\
\hline 1 & $\operatorname{AVR}(H)$ & Secondary AVR (M) & Tertiary AVR (M) + MVR (M) & \\
\hline 1 & LV-aortic conduit $(\mathrm{P})$ & Conduit valve replacement $(\mathrm{M})$ & $\begin{array}{l}\text { Native AVR }(M)+\text { patch } \\
\text { aortic root }\end{array}$ & AICD \\
\hline
\end{tabular}

$\overline{A V R}$, Aortic valve replacement; $M$, mechanical valve; $H$, homograft; $M V P$, mitral valvuloplasty; $L V$, left ventricular; $C A B G$, coronary artery bypass grafting; $A A$, ascending aorta; InnA, innominate artery; $P$, porcine valved; $D A$, descending aorta; $A I C D$, automatic implantable cardioverter-defibrillator; $M V R$, mitral valve replacement.

$(p=0.03)$. By multivariate analysis, the only risk factor for reoperation was associated aortic valve disease $(p=0.02)$.

Sixty-one $(84.7 \%)$ of the 72 late survivors are in NYHA class I, and $11(15.3 \%)$ are in class II. Nineteen patients with mechanical prosthetic valves or atrial fibrillation (or both) were being treated with anticoagulants for prevention of thromboembolism. In addition to the aortic insufficiency mentioned previously, late nonlethal postoperative complications included bacterial endo- carditis $(n=3)$ (one with a left ventricular-aortic conduit, one with an ascending aortic-descending aortic graft, and one with a prosthetic aortic valve) and paroxysmal ventricular tachycardia $(n=1)$.

In both patients in whom a severe pulmonary branch stenosis was relieved by patch enlargement, there was echocardiographic evidence of persisting patency of the pulmonary artery branches. The other 13 patients with unoperated mild or moderate pulmonary branch stenosis remained free of symptoms. 


\section{Discussion}

The relative rarity of SAS has made it difficult to obtain satisfactory data on the natural history, operative indications, and results of surgical therapy for this lesion. The anatomic features of SAS are variable, ranging from a simple supraaortic ridge to hypoplasia of the entire thoracic aorta and beyond. Archer ${ }^{19}$ in 1878 , described an elastic band stretching across and just distal to the insertion of the aortic cusps. Mencarelli, ${ }^{20}$ in 1930, reported a stenotic lesion above the aortic valve, which he called "supravalvular stenosis of the aorta." The first clinical report with catheterization data was by Denie and Verheugt ${ }^{21}$ in 1958, followed by a report by Morrow and colleagues ${ }^{22} 1$ year later. Among the etiologic factors implicated in SAS are idiopathic hypercalcemia, disturbance of vitamin D and calcium metabolism, and rubella, ${ }^{23-28}$ but other factors remain unknown. SAS with mental retardation and typical "elfin" facial appearance was first described by Williams, Barratt-Boyes, and Lowe ${ }^{4}$ and subsequently by Beuren, Apitz, and Harmjanz. ${ }^{16}$ Branch and peripheral pulmonary artery stenosis in association with the same syndrome was described 3 years later by the latter group. ${ }^{17}$ Other extracardiac cardiovascular anomalies that have been reported in association with this syndrome include coarctation of the aorta, ${ }^{29}$ patent ductus arteriosus ${ }^{30}$ and anomalies of the abdominal aorta and its branches. ${ }^{29,31,32}$ Associated intracardiac lesions include mitral valve prolapse, ${ }^{33}$ ventricular septal defect, ${ }^{30,32}$ and tetralogy of Fallot. ${ }^{34}$ Twenty-six of the 28 patients with the nonfamilial form of the Williams-Beuren syndrome in our series were mentally retarded, versus one of the three patients with the familial form of the Williams-Beuren syndrome. A lesser prevalence of mental retardation in the familial form has been reported previously. ${ }^{31,35}$

In all patients with SAS, inspection of the aortic root to rule out obstruction of coronary blood flow is an essential part of the operation. We believe resection of as much supravalvular membrane as possible is also important not only to improve access of blood to the coronary ostia but also to free up the cusps to allow greater mobility. Some patients have anatomic coronary ostial stenosis that may necessitate separate patch enlargement or extension of the aortic patch into the stenotic coronary ostium. ${ }^{36-38} \mathrm{We}$ prefer pericardium for patch material because it is pliable and there is little bleeding from the suture holes. In addition, we have not encountered hemolysis or failure of endothelialization of the patch associated with transient ischemic attacks, as we and others have noted with Teflon or Dacron patches. ${ }^{6} \mathrm{We}^{18}$ have not encountered any late aneurysm formation when pericardium has been used to enlarge the aortic root.

Our experience indicates that enlargement of the aor- tic root with a teardrop-shaped patch leads to excellent long-term results, although this technique may not completely restore the geometry of the aortic sinuses. Important technical points include using a teardrop-shaped rather than a diamond-shaped patch and a patch large enough to restore the aorta to a normal diameter. Patching of $t w 0^{6}$ or three ${ }^{39}$ of the sinuses or circular excision of the stenosis at the level of the sinotubular junction followed by end-to-end anastomosis of the ascending aorta to the aortic root ${ }^{40}$ may restore a more anatomic configuration to the aortic root; our data, however, do not suggest there is any demonstrable early or late advantage to multiple sinus patches with regard to the incidence of persistent or recurrent SAS. The assessment of gradients between the left ventricle and ascending aorta in patients with teardrop- or pantaloon-shaped patches was complicated by the presence of associated aortic valve disease in 20 patients. Nevertheless, the gradients in both groups were low and there was no significant difference between them, even with a considerably longer follow-up in the group of patients with a teardrop-shaped patch. Similarly, there was no difference between the two groups with regard to late development of aortic insufficiency. However, some patients with restricted mobility of the right or left cusps or obstructed blood flow to the coronary ostia may benefit from a two- or three-sinus patch.

Until two decades ago, surgical treatment for the diffuse form of SAS was regarded as an unrewarding undertaking. $8,9,41$ Current techniques including extension of patches into the aortic arch or beyond, as needed to relieve all gradients, and the use of grafts or conduits when necessary now provide excellent early and longterm results. ${ }^{5,12,42} \mathrm{We}$ agree with others ${ }^{6,12}$ that all operations should begin in the aortic root so that any necessary repairs of the aortic valve, subaortic area, or coronary ostial obstructions can be performed. For stenoses extending beyond the aortic arch, we prefer a graft between the ascending aorta and the descending aorta with side branches to any stenotic arch vessels rather than a left ventricular-aortic conduit. Although such a conduit usually completely relieves the gradient between left ventricle and distal aorta, the long-term durability of conduits, particularly those with porcine valves, has been disappointing, and late infection and aneurysm formation have also been reported. ${ }^{43,44}$

Associated aortic valve disease was found to be the major determinant of late death and need for reoperation. In a few cases, reoperation was postponed or delayed, resulting in death from congestive heart failure or death from myocardial failure at the time of reoperation. Accordingly, we believe it is appropriate to reoperate whenever the associated aortic valve disease becomes 
hemodynamically important, as is done for patients with aortic valve disease without SAS.

Another aspect of coronary arterial disease in SAS is the potential for coronary artery dilatation and injury resulting from exposure of the coronary arteries to elevated pressures proximal to the supravalvular ridge, as seen in $48.8 \%$ of our patients. The aortic root hypertension may cause enhanced intimal thickening and accelerated atherosclerosis in the coronary arteries, as found in all six of our autopsied patients. Thickening of the intima and media was found as early as 3 years of age, and all older patients had extensive coronary artery disease with associated myocardial fibrosis and healed infarctions. Two patients in our series underwent concomitant or subsequent coronary artery bypass grafting for coronary artery disease at 22 and 51 years of age, respectively, and one patient died of a myocardial infarction at 39 years of age. These findings illustrate that early treatment of SAS is desirable to prevent this complication.

Repair of severe pulmonary branch stenosis as part of the Williams-Beuren syndrome was performed in two of 15 patients with such stenoses, and adequate long-term patency was maintained in both. The severity of pulmonary branch and peripheral stenoses may lessen with growth of the patient, especially in the mild forms, but some of the severe forms, especially those with peripheral pulmonary stenosis, will not improve or will progress with time. $^{45-47}$

We appreciate the opportunity of including data from patients operated on by Dr. J. W. Kirklin, Dr. D. C. McGoon, and Dr. R. B. Wallace.

\section{REFEREN CES}

1. McGoon DC, Mankin HT, Vlad P, Kirklin JW. The surgical treatment of supravalvular aortic stenosis. J THORAC CardiovasC SuRg 1961;41:125-33.

2. Keane JF, Fellows KE, LaFarge CG, Nadas AS, Bernhard WF. The surgical management of discrete and diffuse supravalvar aortic stenosis. Circulation 1976;54:112-7.

3. Starr A, Dotter C, Griswold H. Supravalvular aortic stenosis: diagnosis and treatment. J THORAC CARDIOvasC SURG 1961;41:134-40.

4. Williams JCP, Barratt-Boyes BG, Lowe JB. Supravalvular aortic stenosis. Circulation 1961;24:1311-8.

5. Shumacker HB Jr, Mandelbaum I. Surgical considerations in the management of supravalvular aortic stenosis. Circulation 1965;31 (Suppl):I36-43.

6. Doty DB, Polansky DB, Jenson CB. Supravalvular aortic stenosis: repair by extended aortoplasty. J THORAC CARDIOvASC SURG 1977;74:362-71.

7. Peterson TA, Todd DB, Edwards JE. Supravalvular aortic stenosis. J Thorac Cardiovasc Surg 1965;50:73441.
8. Cornell WP, Elkins RC, Criley JM, Sabiston DC Jr. Supravalvular aortic stenosis. J THORAC CARDIOvASC SURG 1966;51:484-92.

9. Rastelli GC, McGoon DC, Ongley PA, Mankin HT, Kirklin JW. Surgical treatment of supravalvular aortic stenosis: report of 16 cases and review of the literature. J Thorac Cardiovasc Surg 1966;51:873-82.

10. Weisz D, Hartmann AF Jr, Weldon CS. Results of surgery for congenital supravalvular aortic stenosis. Am J Cardiol 1976;37:73-7.

11. Flaker G, Teske D, Kilman J, Hosier D, Wooley C. Supravalvular aortic stenosis: a 20-year clinical perspective and experience with patch aortoplasty. Am J Cardiol 1983; 51:256-60.

12. Sharma BK, Fujiwara H, Hallman GL, Ott DA, Reul GJ, Cooley DA. Supravalvar aortic stenosis: a 29-year review of surgical experience. Ann Thorac Surg 1991;51:1031-9.

13. Myers JL, Waldhausen JA, Cyran SE, Gleason MM, Weber HS, Baylen BG. Results of surgical repair of congenital supravalvular aortic stenosis. J THORAC CARDIOVASC SURG 1993;105:281-8.

14. Lev M. Autopsy diagnosis of congenitally malformed hearts. Springfield, Ill: Thomas, 1953:53-4.

15. Neufeld HN, Wagenvoort CA, Ongley PA, Edwards JE. Hypoplasia of ascending aorta: an unusual form of supravalvular aortic stenosis with special reference to localized coronary arterial hypertension. Am J Cardiol 1962;10:74651.

16. Beuren AJ, Apitz J, Harmjanz D. Supravalvular aortic stenosis in association with mental retardation and a certain facial appearance. Circulation 1962;26:1235-40.

17. Beuren AJ, Schulze C, Eberle P, Harmjanz D, Apitz J. The syndrome of supravalvular aortic stenosis, peripheral pulmonary stenosis, mental retardation and similar facial appearance. Am J Cardiol 1964;13:471-83.

18. Piehler JM, Danielson GK, Pluth JR, et al. Enlargement of the aortic root or anulus with autogenous pericardial patch during aortic valve replacement. J THORAC CARDIOvASC SURG 1983;86:350-8.

19. Archer RS. Note on a congenital band stretching across the origin of the aorta. Dublin J Med Sci 1878;65:405-6.

20. Mencarelli L. Stenosi sopravalvolare aortica ad anello. Arch Ital Anat Patol 1930;1:829-41.

21. Denie JJ, Verheugt AP. Supravalvular aortic stenosis. Circulation 1958;18:902-8.

22. Morrow AG, Waldhausen JA, Peters RL, Bloodwell RD, Braunwald E. Supravalvular aortic stenosis: clinical, hemodynamic and pathologic observations. Circulation 1959; 20:1003-10.

23. Black JA, Bonham-Carter RE. Association between aortic stenosis and facies of severe infantile hypercalcaemia. Lancet 1963;2:745-8.

24. Garcia RE, Friedman WF, Kaback MM, Rowe RD. Idiopathic hypercalcemia and supravalvular aortic stenosis: documentation of a new syndrome. N Engl J Med 1964; 271:117-20.

25. Friedman WF, Roberts WC. Vitamin D and the supraval- 
vular aortic stenosis syndrome: the transplacental effects of vitamin $D$ on the aorta of the rabbit. Circulation 1966; 34:77-86.

26. Friedman WF. Vitamin D as a cause of the supravalvular aortic stenosis syndrome. Am Heart J 1967;73:718-20.

27. Antia AU, Wiltse HE, Rowe RD, et al. Pathogenesis of the supravalvular aortic stenosis syndrome. J Pediatr 1967; 71:431-41.

28. Varghese PJ, Izukawa T, Rowe RD. Supravalvular aortic stenosis as part of rubella syndrome, with discussion of pathogenesis. Br Heart J 1969;31:59-62.

29. Ino T, Nishimoto K, Iwahara M, et al. Progressive vascular lesions in Williams-Beuren syndrome. Pediatr Cardiol 1988;9:55-8.

30. Morris CA, Demsey SA, Leonard CO, Dilts C, Blackburn BL. Natural history of Williams syndrome: physical characteristics. J Pediatr 1988;1 13:318-26.

31. Ottesen OE, Antia AU, Rowe RD. Peripheral vascular anomalies associated with the supravalvular aortic stenosis syndrome. Radiology 1966;86:430-5.

32. Jones KL, Smith DW. The Williams elfin facies syndrome: a new perspective. J Pediatr 1975;86:718-23.

33. Becker AE, Becker MJ, Edwards JE. Mitral valvular abnormalities associated with supravalvular aortic stenosis: observations in 3 cases. Am J Cardiol 1972;29:90-4.

34. Pernot C, Worms AM, Marçon F, Admant P. Facies de Williams-Beuren avec retard mental et tetralogie de Fallot. Pediatrie 1984;39:53-8.

35. Lewis AJ, Ongley PA, Kincaid OW, Ritter DG. Supravalvular aortic stenosis: report of a family with peculiar somatic features and normal intelligence. Dis Chest 1969; 55:372-9.

36. Martin MM, Lemmer JH Jr, Shaffer E, Dick M II, Bove EL. Obstruction to left coronary artery blood flow secondary to obliteration of the coronary ostium in supravalvular aortic stenosis. Ann Thorac Surg 1988;45:16-20.

37. Dion R, Verhelst R, Matta A, Rousseau M, Goenen $M$, Chalant C. Surgical angioplasty of the left main coronary artery. J THORAC CARdiovasc Surg 1990;99:241-50.

38. Matsuda H, Miyamoto Y, Takahashi T, Kadoba K, Nakano S, Sano T. Extended aortic and left main coronary angioplasty with a single pericardial patch in a patient with Williams syndrome. Ann Thorac Surg 1991;52:1331-3.

39. Kirklin JW, Barratt-Boyes BG. Congenital aortic stenosis. In: Kirklin JW, Barratt-Boyes BG, eds. Cardiac surgery. 2nd ed. New York: Churchill Livingstone, 1993:1 195-237.

40. Chard RB, Cartmill TB. Localized supravalvular aortic stenosis: a new technique for repair. Ann Thorac Surg 1993;55:782-4.

41. Bernhard WF, Keane JF, Fellows KE, Litwin SB, Gross RE. Progress and problems in the surgical management of congenital aortic stenosis. J THORAC CARdIOvaSC SURG 1973;66:404-19.

42. Merin G, Copperman IJ, Borman JB. Surgical correction of diffuse supravalvular aortic stenosis involving the branches of the aortic arch. Chest 1976;70:546-9.
43. DiDonato RM, Danielson GK, McGoon DC, Driscoll DJ, Julsrud PR, Edwards WD. Left ventricle-aortic conduits in pediatric patients. J THORAC CardiovasC SuRG 1984;88:82-91.

44. Sweeney MS, Walker WE, Cooley DA, Reul GJ. Apicoaortic conduits for complex left ventricular outflow obstruction: 10-year experience. Ann Thorac Surg 1986; 42:609-11.

45. Giddins NG, Finley JP, Nanton MA, Roy DL. The natural course of supravalvar aortic stenosis and peripheral pulmonary artery stenosis in Williams's syndrome. Br Heart $\mathbf{J}$ 1989;62:315-9.

46. Wren C, Oslizlok P, Bull C. Natural history of supravalvular aortic stenosis and pulmonary artery stenosis. $\mathrm{J}$ Am Coll Cardiol 1990;15:1625-30.

47. Zalzstein E, Moes CAF, Musewe NN, Freedom RM. Spectrum of cardiovascular anomalies in Williams-Beuren syndrome. Pediatr Cardiol 1991;12:219-23.

\section{Discussion}

Dr. Joseph J. Amato (New Hyde Park, N.Y.). We have used both the classic approach of patch repair for SAS and the pantaloon approach as proposed by Dr. Doty. Most recently, however, we have also used the technique described by Dr. Gerald Brom and most recently written about by Dr. John Meyers of Hershey. The aorta is transected and three equally shaped triangular patches are used to enlarge the stenotic region, after which the aorta is reattached. The reason for this approach is that there is less insufficiency because of the equality of the cusps. For the sake of completeness, I wonder if the authors have used this technique or any modification thereof and would wish to comment upon it.

Dr. van Son. We have not used the technique you mentioned, which was first proposed by Brom in 1978 and later modified by Meyers, Waldhausen, and colleagues. Our experience indicates that enlargement of the aortic root with the teardrop-shaped or pantaloon-shaped patch techniques both lead to excellent longterm results in terms of survival, late gradient, and late aortic insufficiency, although we realize that the latter techniques may not perfectly restore the geometry of the aortic root. We believe that, in general, it is not necessary to use the Brom technique, although this modification may have application in selected patients with significant distortion of the aortic root, often with apposition of the aortic valve cusps to the obstructing ridge of the SAS with resulting coronary ostial stenosis, because this technique effectively separates the aortic cusps from the commissures. A minority of patients with severe ostial stenosis may require additional patch enlargement of the coronary ostium, either by extension of the aortic patch or by a separate patch.

Mr. Jaroslav F. Stark (London, United Kingdom). In our experience with SAS we have encountered problems with long stenosis of the left and right pulmonary arteries. On angiogram or echocardiogram these arteries have abnormal pulsation right to the hilum. Even patching these arteries from the bifurcation to the hilum did not relieve the stenosis. I noticed that you reported 15 pulmonary artery stenoses but only two procedures. Could you comment please?

Dr. van Son. In our series there were 15 patients with discrete pulmonary artery stenoses, primarily of the proximal branches. 
In four of these patients the stenosis extended beyond the upper lobe bifurcation. Only two patients had proximal stenoses severe enough to warrant operative treatment and both received patches. In the other 13 patients, the stenoses were either mild or moderate or too far peripherally, and nothing was done to them. At late postoperative follow-up, there was echocardiographic and angiographic evidence of improvement of the degree of stenosis in the majority of patients who did not have surgical relief of the stenosis. In both patients who had surgical relief of their pulmonary stenosis, the pulmonary arteries were widely patent. These results indicate that the presence of discrete pulmonary artery stenosis should generally not be a contraindication to surgical relief of SAS. We agree that diffuse hypoplasia of the pulmonary arteries poses a difficult problem and some of these lesions may be beyond surgical relief.

Dr. Luiz Carlos Bento de Souza (São Paulo, Brazil). Since 1991 , in five patients with a localized form of SAS, we have used a technical modification that permits an enlargement of the aortic root with autologous ascending aortic wall, which avoids prosthetic material.
During the last meeting of this Association, Dr. John Meyers from Hershey, Pennsylvania, reported his experience with this technique.

After transecting the aorta just above the stenotic site and trimming off the thickened tissue, we make three vertical incisions in the Valsalva sinuses. Distally we make three longitudinal incisions corresponding to the commissural parts, obtaining three flaps that will be sutured in the Valsalva sinuses.

At the end we have a sinusoidal line of suture going up on the commissures and down on the Valsalva sinuses. With this technique, we are able to operate early in the patient's life, avoiding complications on the aortic valve, coronary arteries, and left ventricular hypertrophy and the possibility of inadequate growth of the aortic root.

In our most recent eight Jatene procedures for transposition of the great arteries, we have used this technique to reconstruct the pulmonary artery trunk to prevent pulmonary stenosis in the late postoperative period. 